\title{
Sensitivity to Painful and Nonpainful Electrocutaneous Stimuli in Monkeys: Effects of Anterolateral Chordotomy
}

\author{
Joel D. Greenspan, Charles J. Vierck, Jr., ${ }^{\star}$ and Louis A. Ritz $\dagger$ \\ Department of Physiology, University of North Carolina School of Medicine, Chapel Hill, North Carolina 27514, \\ *Department of Neuroscience, University of Florida College of Medicine, Gainesville, Florida 32610, and \\ †Departments of Neurological Surgery and Neuroscience, University of Florida College of Medicine, \\ Gainesville, Florida 32610
}

Four Macaca nemestrina monkeys were trained to pull a manipulandum to escape electrocutaneous stimulation (ES) applied to either leg. The intensities of stimulation which the monkeys chose to escape were those that humans identify as painful. The duration of escape trials was inversely related to stimulus intensity, and the force of escape responses was directly related to ES intensity. Reflexive responses were elicited by stimulus intensities below and above the escape threshold, and the force of the flexion reflexes was a negatively accelerating function of stimulus magnitude. The monkeys were also trained to respond, for water reinforcement, to cued, low-intensity ES. The stimulus intensities detected for water reinforcement were 50-100 $\times$ less than the escape thresholds.

Following unilateral, anterolateral chordotomy, all monkeys demonstrated a large reduction in percentage of escape responding to stimulation of the contralateral leg. When the animals did escape contralateral stimulation, the latencies to respond were longer than preoperatively. The percentage and latency of escape responses to stimulation of the ipsilateral leg were not changed following chordotomy. Despite the depression of contralateral pain reactivity, the animals continued to respond to low levels of stimulation on the detection task, demonstrating that anterolateral chordotomy reduced the painfulness of strong stimulation without climinating sensibility for low levels of stimulation. However, postoperative detection thresholds were consistently higher contralaterally than ipsilaterally. This effect resulted from slight contralateral decreases and significant ipsilateral increases in sensitivity to low levels of ES (relative to preoperative values). Thus, contralateral axons in the anterolateral column contribute to detection of light cutaneous stimulation, and chordotomy appears to disinhibit inputs from large myelinated afferent fibers to ipsilateral neurons in the spinal gray matter caudal to the lesion.

The strictly contralateral slowing and reduction in percentage of pain reactivity by chordotomy correlated with reports from human patients. However, reflexive measures did not suffice as indicants of pain sensitivity. The chordotomies produced bilateral attenuations of reflexive amplitudes. Also, the force of operant escape responses was reduced with stimulation of either side. Thus, the disfacilitation of motoric reactions extended both

Received Feb. 8, 1985; revised July 25, 1985; accepted July 26, 1985.

This research was supported primarily by program project Grant NS 14899 from the National Institute of Neurological and Communicative Disorders and Stroke. Additional support was provided from Grants NS 06347, NS 06835, NS 07261 , and NS 07166. The technical assistance of Michael Young is gratefully acknowledged.

Correspondence should be addressed to Dr. Joel D. Greenspan, Department of Physiology, 206-H, Iniversity of North Carolina, Chapel Hill, NC. 27514.

Copyright (C) 1986 Society for Neuroscience $0270-6474 / 86 / 020380-11 \$ 02.00 / 0$ rostral and caudal to the spinal lesions that interrupted propriospinal axons in the vicinity of the ventral horns.

Pain psychophysics involving nonhuman animals have a long history and numerous interpretive quagmires (for reviews, see Lineberry, 1981; Vierck and Cooper, 1984; Wood, 1984). Many experiments have assessed pain with frankly or potentially reflexive measures, such as the tail-flick (D'Amour and Smith, 1941) or flinch-jump (Evans, 1961) reactions. Apparently more purposive, untrained reactions to a hot plate have been noted (Woolfe and MacDonald, 1944) and compared directly to reflexive measures (Jacquet and Lajtha, 1976; Yaksh and Rudy, 1976), but skin temperature has not been measured in either case (to establish that the reactions are nociceptive), and controls for direct motor effects are seldom included. Another common method trains animals to terminate stimuli presented in a sequence (Weiss and Laties, 1970) that can be manipulated by the animals to remain below painful levels.

In order to interpret a treatment as a specific modulator of pain sensations, it is necessary to establish that the manipulation does not have direct motor effects, to compare similar or identical reactions to innocuous and painful stimuli, and to differentiate reflexive from operant reactions. Accordingly, the present study assesses (1) operant escape by the forelimbs from aversive stimuli applied to the hindlimbs, (2) operant detection of nonaversive stimuli, and (3) reflexive reactions of the hindlimbs to stimuli below and above threshold for escape reactions. These behaviors have been used to assess the effects of thoracic anterolateral chordotomies, which interrupt the ascending spinothalamic tract from the contralateral hindlimb. The lesions have been made at thoracic levels to leave the forelimbs free from effects resulting from involvement of descending pathways. Modulatory functions of the descending pathways can be assessed by noting changes in reflexive responses of the hindlimbs to the electrocutaneous stimulation (ES).

Anterolateral chordotomy in humans produces substantial attenuation or loss of contralateral pain elicited by cutaneous stimulation from thermal, mechanical, or electrical sources (e.g., Vierck et al., 1985; White and Sweet, 1969), and therefore it is expected that the monkeys' aversive reactions to ES would be decreased contralaterally for normally painful intensities. A previous investigation has shown this to be the case (Vierck and Luck, 1979), suggesting that the pain pathways of subhuman primates are organized similarly to those of humans; this provides an appropriate experimental model for investigation of principles of pain coding and control. This is important to establish because of considerable phylogenetic differences in the organization of pathways subserving pain (Kennard, 1954; Kevetter and Willis, 1984; Mehler, 1969). However, the previous 


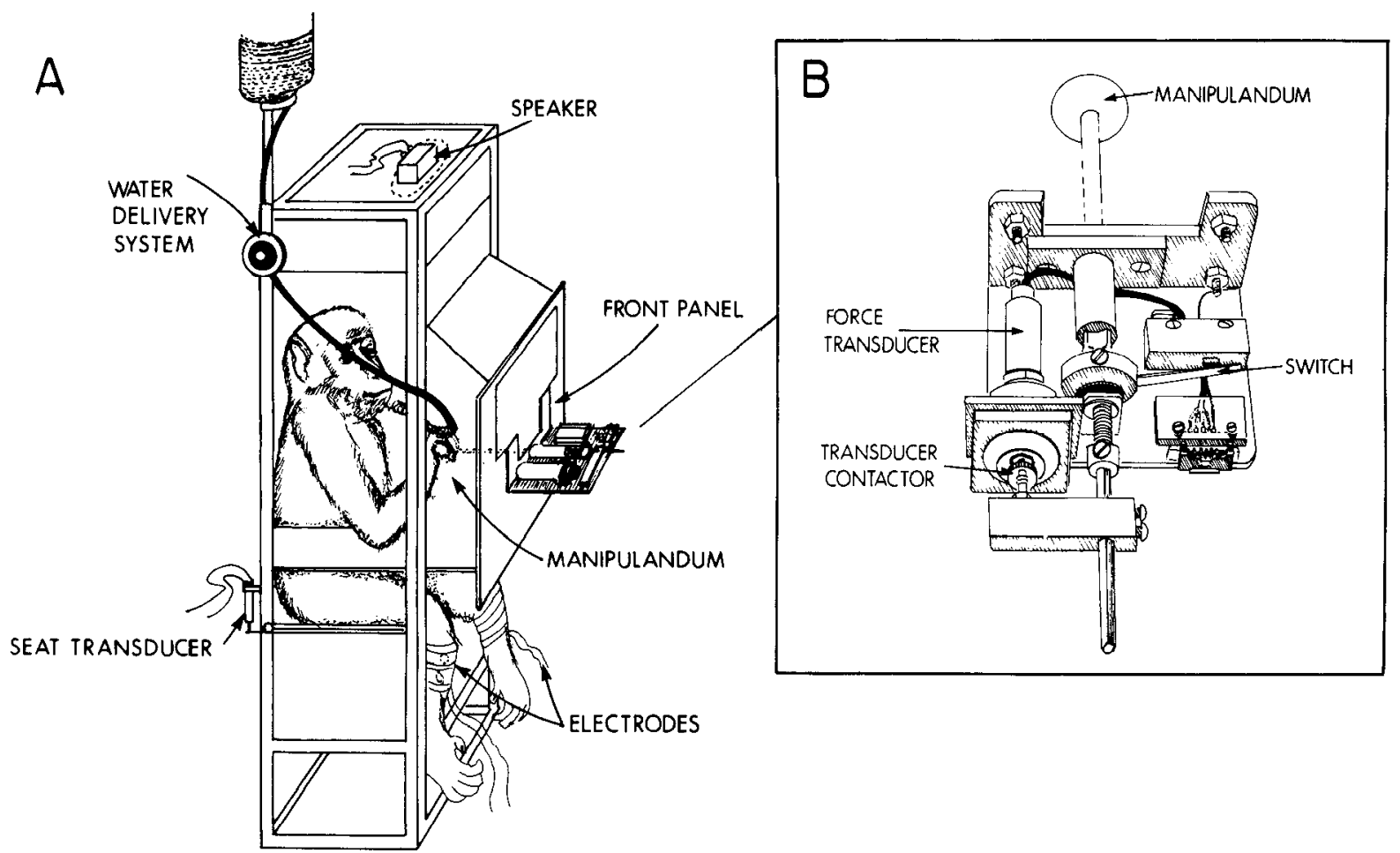

Figure 1. The essential features of the testing apparatus are shown diagrammatically. The animals are loosely restrained by a tray that slides in the testing chair and fits around the waist. Electrode pairs are taped to the lateral calf of each leg, and loose fitting ankle straps prevent the animals from grasping the electrodes or the wires with their feet. The front panel (attached to the tray) is made of clear plexiglass, permitting observation of the animals through a one-way window in the sound-insulated testing room. The manipulandum (shown in the insert, B) protrudes through the front panel. Pulling the manipulandum activates a switch near the midpoint of the available excursion, and then the load cell of a force transducer is contacted by a sidearm extension of the manipulandum assembly, stopping movement toward the animal. A second force transducer and load cell are positioned above an extension of the hinged seat, measuring the static weight of the animal and recording the magnitude of flexion responses by translating upward movement of a leg against the tray into a down-going force on the seat. Auditory cues are provided by a speaker in the top of the enclosure, and water reinforcement is delivered via a tube that extends into the testing chamber.

investigation did not establish whether the effect of chordotomy in monkeys was selective for pain sensations, leaving detection of non-nociceptive stimulation intact.

Human chordotomy patients are able to detect light tactile stimulation normally or with subtle elevations of threshold (Walker, 1940; White and Sweet, 1969), clearly contradicting early reports that sensations of light touch depend upon contralateral spinal conduction (Brown-Sequard, 1868; Head and Thompson, 1906; May, 1906; Petren, 1902). For subhuman primates, it has been established that thresholds for light touch are unchanged following interruption of the ipsilateral lemniscal pathways in the dorsal and dorsolateral columns (Vierck, 1977), indicating an important contribution by contralateral pathways, but the effect of anterolateral chordotomy on touch detection has not been determined. That is, simple recognition of light touch may be served redundantly by the spinal pathways such that neither contralateral nor ipsilateral lesions alone produce elevations of thresholds.

\section{Materials and Methods}

\section{Subjects}

Four adolescent, female pig-tailed monkeys (Macaca nemestrina) were the subjects in this experiment. The monkeys were provided food ad libitum in their home cages and received water during and after the experimental sessions. The animals were maintained in animal care facilities fully accredited by the American Association for Accreditation of Laboratory Animal Care.

\section{Stimulus}

A BRS/LVE programmable (titrating) shocker provided $60 \mathrm{~Hz}$ alternating, constant current to the midlateral surface of either lower leg, via pairs of stainless steel electrodes. The stimulation sites on the legs were tattooed to ensure consistent electrode placement. The electrodes were placed over wells of conductive electrode paste, surrounded by foam pads, and securely taped. The surface area of each electrode-skin contact point was $10 \mathrm{~mm}^{2}$. The two wells on each leg were separated by $1 \mathrm{~cm}$. The current was interrupted ( $40 \mathrm{msec}$ on, $200 \mathrm{msec}$ off) to minimize sensory adaptation to low levels and to reduce the total exposure time to painful intensities of current.

\section{Behavioral procedure}

The monkeys were tested with two types of trials: (1) detection trials, in which pulling a manipulandum once during low-intensity ES, preceded by a tone, resulted in water reinforcement; and (2) escape trials, in which an unsignaled, high-intensity ES could be terminated by two successive pulls on the same manipulandum (Table 1).

For the detection trials, monkeys were first trained to pull the manipulandum for water reinforcement (see Fig. 1). When they performed this task with regularity, a tone was introduced to define trial periods; water was delivered only when manipulandum pulls occurred during presentation of the tone. When the monkeys began to restrict their

Table 1. Conditions for detection trials and escape trials during data collection

\begin{tabular}{lll} 
& Detection trials & Escape trials \\
\hline Antecedents & Tone and ES & ES \\
& $\left(0.003-0.1 \mathrm{~mA} / \mathrm{mm}^{2}\right)$ & $\left(0.1-2.5 \mathrm{~mA} / \mathrm{mm}^{2}\right)$ \\
Behavior & A single manip- & Two manipulandum \\
& ulandum pull & pulls \\
Consequence & Water reinforcement & Termination of ES \\
\hline
\end{tabular}



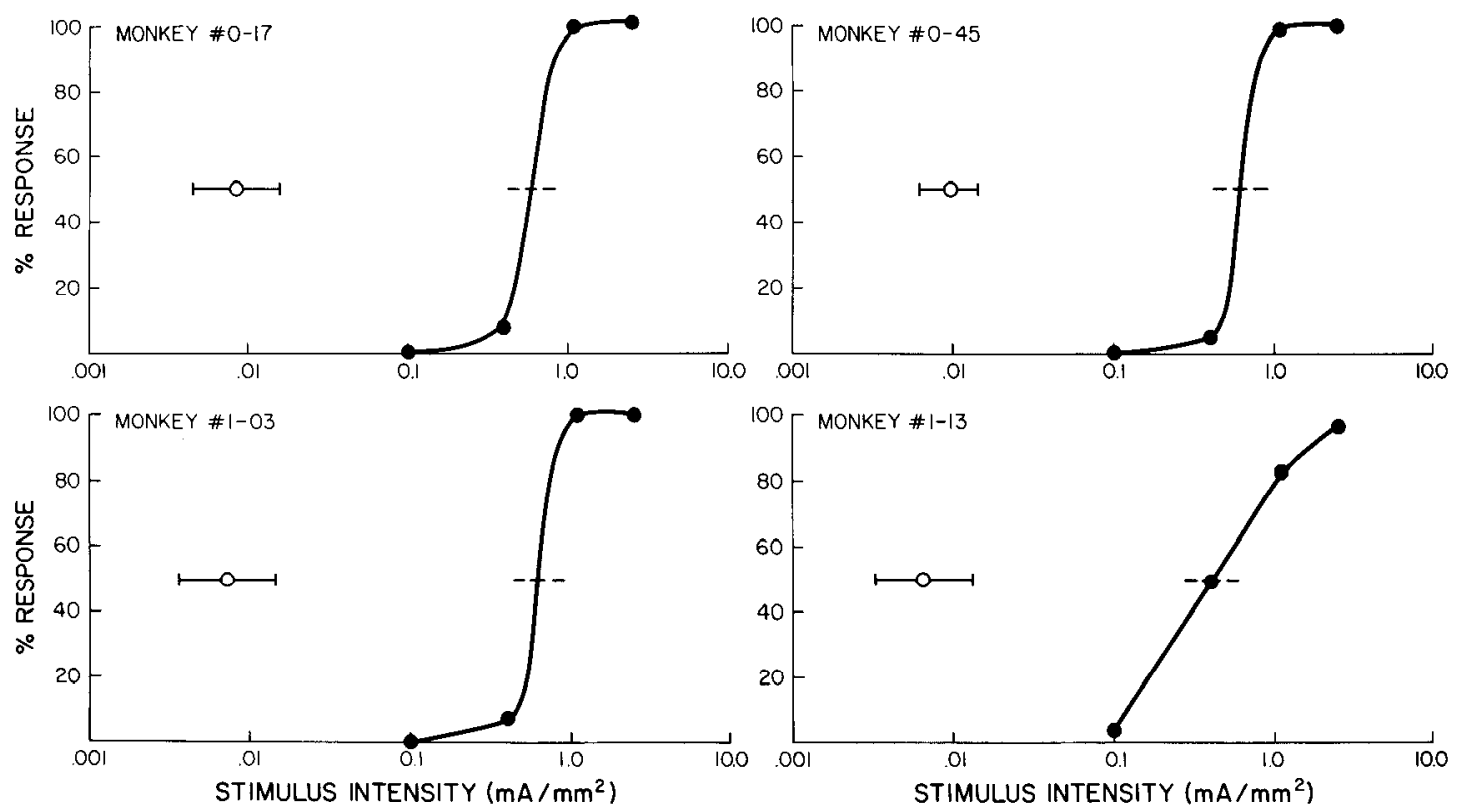

Figure 2. Thresholds for detection and escape are shown for the four monkeys tested on the paradigm that includes cued trials with water reinforcement for responses during low-intensity ES (detection; open circles) and uncued trials with ES termination as the only reinforcer (escape; closed circles). Detection thresholds were calculated as the geometric means of the staircase reversal values, approximating $50 \%$ correct responding. Standard deviations from geometric means of detection thresholds (in $\mathrm{mA} / \mathrm{mm}^{2}$ ) are shown as horizontal bars. Escape thresholds (50\% escape) are indicated by dashed lines on curves fitted by eye to points corresponding to the average percentage of escape responses during stabilized preoperative performance ( 2 or 3 months) with presentation of ES on the escape task.

operant behavior to the tone periods, a low-intensity current $(0.02-0.05$ $\mathrm{mA} / \mathrm{mm}^{2}=0.2-0.5 \mathrm{~mA}$ between the $10 \mathrm{~mm}^{2}$ electrode-skin contact areas) was presented simultaneously with the tone. The ES intensity was gradually raised to $0.1 \mathrm{~mA} / \mathrm{mm}^{2}$, and a delay was placed between onset of the tone and onset of the subsequent ES. From this point in the training sequence, water reinforcement was contingent upon manipulandum pulls during ES and tonc. If a monkcy pulled the manipulandum during the tone, but before the ES was to be delivered, the ES was not given. Thus, an anticipatory response (i.e., a pull during tone alone) precluded the opportunity for water on that trial. The final parameters for the detection trials were as follows: Tone was presented for $10 \mathrm{sec}$. Tone onset was followed by a random delay period of $0.5-$ $8.0 \mathrm{sec}$ before ES was delivered for $2 \mathrm{sec}$. Responses during ES produced immediate water reinforcement and ES termination, but the tone remained on for the entire $10 \mathrm{sec}$ period. After tone offset there was a 10 sec intertrial interval before the next trial.

The ES intensities used for the detection trials were determined by the staircase method (Cornsweet, 1962). The first detection trial on each leg began with a $33.5 \mu \mathrm{A} / \mathrm{mm}^{2}$ stimulus. If the monkey "hit" (i.e., pulled the manipulandum during the ES) on that trial, the intensity was reduced by $3.35 \mu \mathrm{A} / \mathrm{Im}^{2}$ for the next trial. If the monkey did not pull during the ES, the intensity was increased by $3.35 \mu \mathrm{A} / \mathrm{mm}^{2}$ for the next trial. Thus, the intensity delivered on each trial was a function of performance on the previous trial. Two independent staircases were maintained, one for each leg.

During the training period, escape trials were initially similar to detection trials in that the ES was cued by a tone (0.5-1.0 sec delay) but was of a higher intensity $\left(0.2 \mathrm{~mA} / \mathrm{mm}^{2}\right)$. Over a period of weeks, the intensity was gradually raised to a maximum of $2.50 \mathrm{~mA} / \mathrm{mm}^{2}$, while checking to make sure that each monkey was performing regularly. At this juncture, the escape trials were made distinct from the detection trials by (1) removal of the tone cue, (2) removal of the water reinforcement, and (3) a requirement of two manipulandum pulls to terminate the ES (see Table 1). If an animal did not escape stimulation, the current was terminated after $5 \mathrm{sec}$.

The ES intensities used for the escape trials during data collection were fixed at $0.1,0.4,1.1$, and $2.5 \mathrm{~mA} / \mathrm{mm}^{2}$. These intensities were chosen on the basis of human psychophysical studies under similar conditions (Vierck et al., 1983b) to span a range from well below pain threshold through suprathreshold levels that are tolerable. The order of ES intensities was fixed such that all sessions began with an escape trial at $0.1 \mathrm{~mA} / \mathrm{mm}^{2}$, and four series of escape trials were presented in the order, $0.1,0.4,1.1,2.5,2.5,1.1,0.4,0.1 \mathrm{~mA} / \mathrm{mm}^{2}$. After each ascending series, stimulation for escape trials was switched to the opposite leg. The first trial was delivered to the left or the right leg on alternate days. The sequence of trials was structured so that two detection trials followed each escape trial. The leg receiving ES on a detection trial was always opposite the one receiving stimulation on the most recent escape trial. The interstimulus interval was $10 \mathrm{sec}$ following detcetion trials and 20 sec following escape trials. In each session, 32 detection trials and 16 escape trials involved stimulation of each leg.

Many aspects of this procedure minimized pain and stress for the monkeys. The monkeys were adapted fully to each variant of the experimental paradigm, and painful levels of stimulation were introduced gradually and only after the animals were fully trained to respond appropriately. At all times during the session, the monkeys were able to terminate ES by pulling the manipulandum. The parameters of electrical stimulation used in this study have been applied previously to the same cutaneous region of both humans and monkeys and have never produced observable tissue damage (Vierck and Luck, 1979; Vierck et al., $1983 \mathrm{a}, \mathrm{b})$. All evoked sensations are brief and can be tolerated readily, as indicated by human reports and by the monkeys' willingness to enter the testing apparatus.

\section{Response measures}

For both types of trials, the force and timing of manipulandum pulls were recorded. The force of each pull was measured by a StathamGould Z28 force transducer, which was mounted on the front panel of the restraint chair (Fig. $1 B$ ). The electrical signal from this transducer was fed to a DC amplifier, and then to an A/D input board of a PDP 11/03-L computer. The latency of each manipulandum pull was measured relative to ES onset by a microswitch located on the chair's front panel. Reflexive force was measured with another Statham-Gould Z28 force transducer, depicted in Figure $1 A$ as the seat transducer. Reflexive flexion appeared as a discrete event within $100 \mathrm{msec}$ of ES onset, and to guarantee that the maximal force was stored, reflex recording occurred within a window of $200 \mathrm{msec}$ following ES onset. The reflexive responses were not instrumental in reducing the intensity or duration of ES.

The computer-controlled stimulus presentations recorded the response measures and provided for the independent operation of two training/testing stations. The output of the stimulators was monitored by a Techtronix storage oscilloscope to verify that proper levels of current were delivered. 
A.

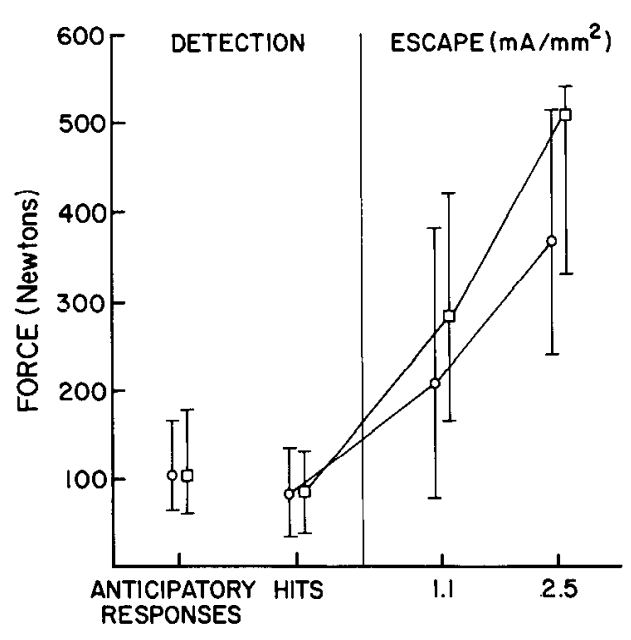

B.

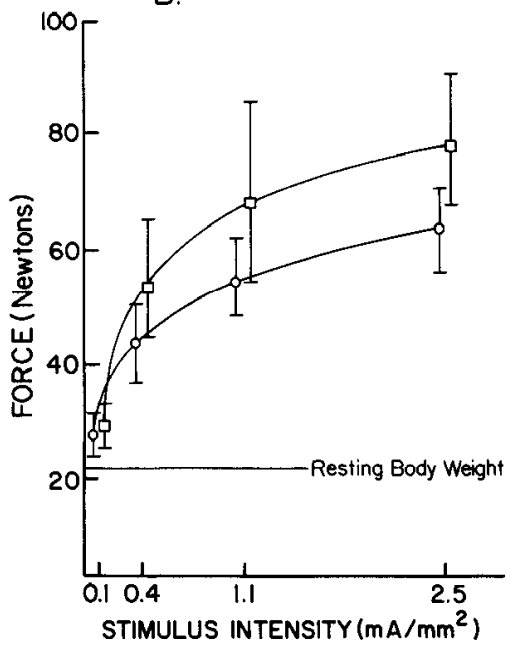

C.

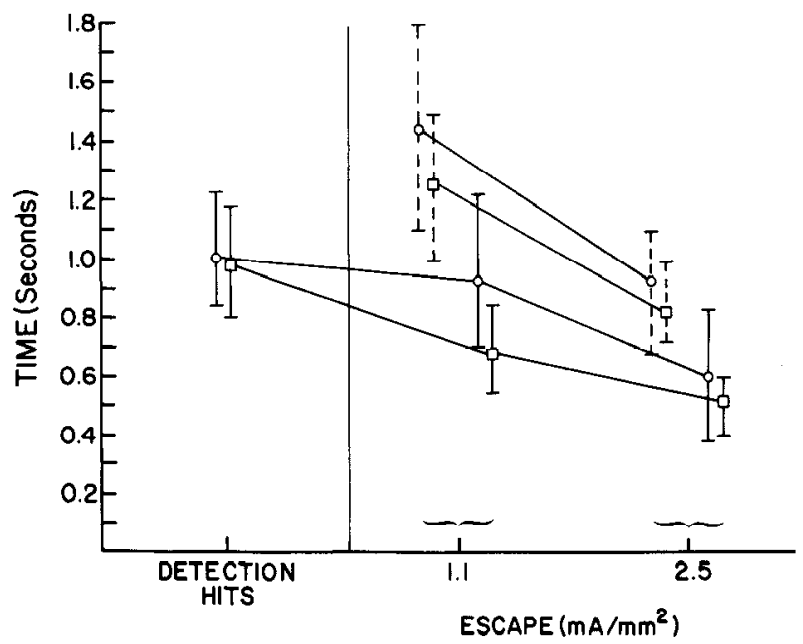

Figure 3. Data from one representative animal (monkey 0-17). Data points represent median values from individual responses. Interquartile ranges are shown as vertical lines. $A$, With stimulation of the left (circles) or right (squares) legs, the operant forces exerted on anticipatory or correct responses on the detection task (left panel) are shown in relation to responses to different stimulus intensities on the escape task (right panel). $B$, Reflexive responses of the stimulated legs increased as a negatively accelerated function of ES intensities below escape threshold $(0.1$ and 0.4 $\left.\mathrm{mA} / \mathrm{mm}^{2}\right)$ and above escape threshold $\left(1.1\right.$ and $\left.2.5 \mathrm{~mA} / \mathrm{mm}^{2}\right)$. $C$, Latencies of the first response (right panel; solid vertical lines) and second response (dashed vertical lines) on escape trials are shown in relation to latencies of detection responses (left panel).

\section{Surgical procedure}

After a monkcy had gencrated at lcast 2 months of stable data, a unilateral, anterolateral chordotomy was performed under sterile conditions, while the monkey was deeply anesthetized with Metaphane. Following laminectomy, the right anterolateral tract was severed at an upper thoracic level, from above the dentate ligament to the ventral midline. After allowing 1 week for recovery from the surgery, the daily testing routine was begun again.

Between 10 and 15 months after the chordotomy, the monkeys were sacrificed under deep pentobarbital anesthesia by intracardial perfusion with an aldehyde fixative. The area around the lesion site was removed and embedded in celloidin for serial sectioning. Alternate spinal cord sections were treated with Mahon and Nissl stains.

\section{Data analysis}

Escape data. The response measures derived from the operant escape task included (1) the percentage of stimuli escaped at each intensity, (2) the latency of escape responses (i.e., manipulandum pulls during FS), and (3) the force of escape responses. Because escape percentage best differentiates mild to moderately nociceptive stimuli $(0.4 \mathrm{vs} 1.1 \mathrm{~mA} /$ $\mathrm{mm}^{2}$ ), but latencies of escape best discriminate moderate to high ES levels (1.1 vs $\left.2.5 \mathrm{~mA} / \mathrm{mm}^{2}\right)$, a measure of trial durations was derived as a combination of escape percentage and latency. For each monkey, a histogram of escape latencies was examined at stimulus intensities at which an animal escaped at least $40 \%$ of the time. This was done separately for each leg, for 2 or 3 months of preoperative data, and 3 months of postoperative data. The 95 th percentile point was determined for each distribution. The largest value derived for each animal was that animal's trial duration cutoff point. Thus, trial durations consisted of escape latencies when responses occurred (i.e., the time between ES onset and a second bar pull) or the cutoff value when no escape occurred. Geometric means of modified trial durations combine the percentage and escape latency measures conservatively, without undue distortion from inclusion of maximal trial durations (arbitrarily set at $5 \mathrm{sec}$ ) that exceed the range of latencies emitted by the animals (see Vierck et al., 1983a, for a more detailed explanation). The cutoff values in seconds for the four monkeys were 2.375 (monkey $0-17), 2.875(0-45), 2.45$ (1-30), and 3.45 (1-13).

Detection data. Detection thresholds were calculated on the basis of staircase reversals, as described by Gescheider (1976). Specifically, a reversal value was recorded as the midpoint between adjacent stimulus intensities that were detected and not detected. In most cases, the monkeys maintained the stimulus intensities within two or three steps throughout a session and would confine responses to the tone and ES interval. However, there were two types of response bias that were occasionally observed. If a monkey made anticipatory responses at a high rate, false-positive responses were likely to occur, driving threshold values down inappropriately. Therefore, reversal values were excluded that were immediately preceded by two or more anticipatory responses. This excluded runs occurring in clusters (e.g., at the beginning of the sessions) and comprised 172 of 2998 threshold values (5.7\%) obtained during the last preoperative month and the first postoperative month of all four monkeys.

Occasionally, an animal would respond infrequently on detection trials (usually near the end of a session, when satiated), producing extremely high reversal values in what was an otherwise tight distribution. These outliers were discarded if they were not in continuity with the 


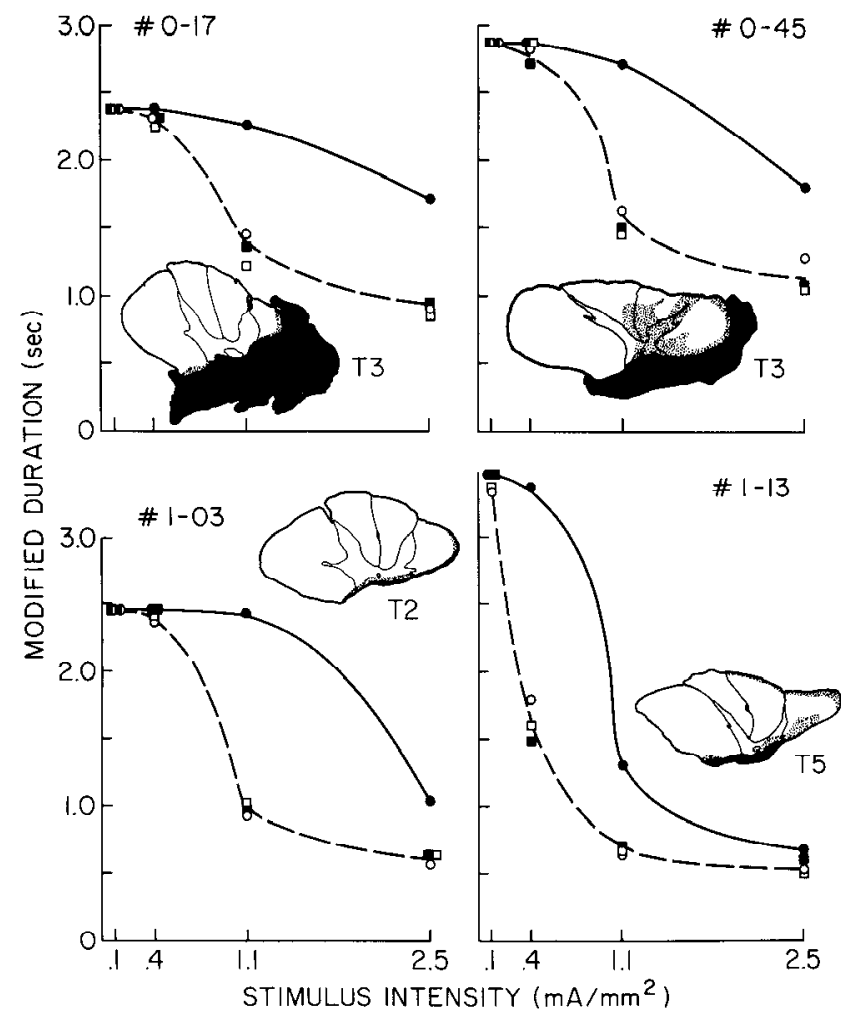

Figure 4. Geometric means of trial durations as a function of stimulus intensities presented on the escape task for four monkeys. Following anterolateral chordotomies on the right side, trial durations were elevated with stimulation of the left leg (solid circles) relative to postoperative performance with stimulation of the right leg (solid squares) or preoperative values from stimulation of either leg (open symbols). Drawings of the lesion configurations indicate the area of dense scar tissue and an absence of fibers by black and the presence of gliosis by stippling. The levels of the lesions are indicated near each drawing.

distribution of the main body of data, which resulted in the exclusion of 58 of 2998 values $(1.9 \%)$.

Statistical analysis. $\Lambda$ repeated-measures analysis of variance (ANOVA) was performed on each of four dependent variables: modified trial duration, escape force, reflex force, and detection threshold (Bruning and Kintz, 1968; Edwards, 1985). The entries for each ANOVA consisted of values generated by stimulation of each leg, averaged for each animal over the last preoperative month and over the first postoperative month. Geometric means were calculated for trial durations and detection thresholds and medians were used for escape forces and reflex forces. For the modified-duration and escape-force analyses, only data related to the two highest stimulus intensities were used, because three of the four animals ordinarily did not escape the two lower intensities. However, reflexive responses were reliably evoked by the three higher stimulus intensities, and therefore data from these trials were used for analysis of reflexes.

\section{Results}

\section{Preoperative data}

Figure 2 presents detection thresholds and percentages of escape responding, averaged over the last preoperative month for each of four monkeys. It is clear that the thresholds for escapebetween 0.4 and $1.1 \mathrm{~mA} / \mathrm{mm}^{2}$ for all monkeys-were considerably higher than the detection thresholds (between 0.005 and $0.01 \mathrm{~mA} / \mathrm{mm}^{2}$ ). Furthermore, even though the animals had the opportunity to terminate the $0.1 \mathrm{~mA} / \mathrm{mm}^{2}$ stimulus during escape trials, this occurred on only one trial (for monkey 1-13). These data demonstrate that the monkeys clearly distinguished between the detection and escape tasks.

Other aspects of the animals' performance showed differen-
Table 2. Results of repeated-measures ANOVA

\begin{tabular}{lcc} 
& $F$ value & $p$ \\
\hline Modified trial duration & & \\
Stimulus intensity & 36.0 & $<0.01$ \\
Leg & 23.2 & $<0.025$ \\
Operative condition & 60.0 & $<0.005$ \\
Leg $\times$ operative condition & 26.0 & $<0.025$ \\
$\quad$ Ipsi vs contra, pre-op & 1.2 & N.S. \\
Ipsi vs contra, post-op & 27.0 & $<0.025$ \\
Pre vs post, contra & 37.5 & $<0.01$ \\
Pre vs post, ipsi & 0.7 & N.S.
\end{tabular}

Detection threshold

$\begin{array}{lrc}\text { Leg } & 2.3 & \text { N.S. } \\ \text { Operative condition } & 14.2 & <0.05 \\ \text { Leg } \times \text { operative condition } & 12.0 & <0.05 \\ \text { Ipsi vs contra, pre-op } & 0.4 & \text { N.S. } \\ \text { Ipsi vs contra, post-op } & 60.1 & <0.005 \\ \text { Pre vs post, contra } & 7.1 & \text { N.S. } \\ \text { Pre vs post, ipsi } & 16.5 & <0.05\end{array}$

Reflex force

Stimulus intensity

0.4 vs $1.1:$ mean difference $=10.4$

$27.2<0.001$

1.1 vs $2.5:$ mean difference $=5.8$

$<0.005^{b}$

Leg

$<0.05^{b}$

Operative condition

N.S.

Leg $\times$ operative condition

$<0.025$

N.S.

Intensity $\times$ operative condition

$<0.025$

Pre vs post, 0.4

$<0.05$

Pre vs post, 1.1

$<0.01$

Pre vs post, 2.5

$<0.01$

Escape force

$\begin{array}{lll}\text { Stimulus intensity } & 11.8 & <0.05 \\ \text { Leg } & 12.1 & <0.05 \\ \text { Opcrative condition } & 14.8 & <0.05\end{array}$

${ }^{a}$ All interaction terms not displayed were not significant (N.S.).

${ }^{b}$ Based on Duncan's multiple-range test.

tiation between the two operant tasks. Data from monkey 0-17 (Fig. 3A) are representative of all monkeys and show that the manipulandum was pulled harder to terminate strong intensities on the escape task than to anticipate or respond currently (hit) on the detection task. This occurred consistently, despite the fact that the same minimal force was sufficient to accomplish either task. Furthermore, three of the monkeys' response forces clearly were graded in proportion to stimulus intensity on escape trials. This trend is often, but not always, seen with monkeys and has been confirmed with humans under similar testing circumstances (Vierck et al., 1983a, b).

Figure $3 C$ presents preoperative latency data for monkey $0-17$ that were similar to those for all the monkeys. The average of each monkey's median latencies for detection responses to stimulation of either leg was $1.011 \mathrm{sec}$, which was slightly longer than the median latency for the first pull of an escape response to $1.1 \mathrm{~mA} / \mathrm{mm}^{2}(0.670 \mathrm{sec})$. The latency measure consistently differentiated the high from the intermediate intensities of stimulation on the escape task. Shorter latencies were observed for the first and second pulls to terminate $2.5 \mathrm{~mA} / \mathrm{mm}^{2}(0.487$ and $0.770 \mathrm{sec}$ ), as compared with the first and second pulls in response to $1.1 \mathrm{~mA} / \mathrm{mm}^{2}(0.670$ and $1.035 \mathrm{sec})$. Significant dif- 


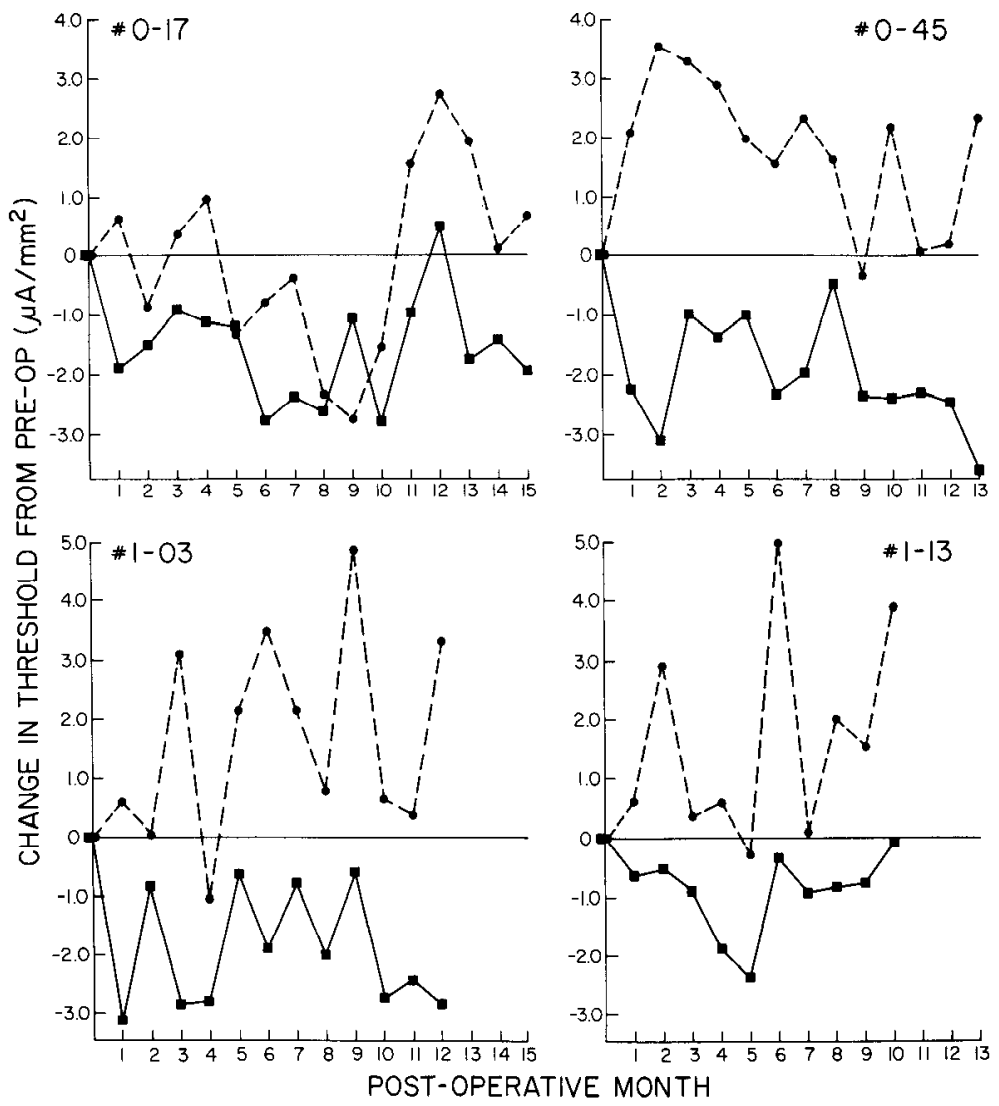

Figure 5. Postoperative changes in ipsilateral detection thresholds (solid lines connecting squares) and contralateral thresholds (dashed lines connecting circles), compared to preoperative values averaged over 2 months (1-13) or 3 months. Difference scores below the 0-line represent hypersensitivity (lower thresholds); points above the 0-line indicate threshold elevations from preoperative means.

ferentiation of stimulus intensities by escape latencies was obtained by statistical analysis of modified trial durations (Table 2).

Figure $3 B$ shows the forces of reflexive responses to stimuli on escape trials. All monkeys exhibited little or no reflexive reaction to the $0.1 \mathrm{~mA} / \mathrm{mm}^{2}$ stimulus, but reflexive flexion occurred reliably to $0.4 \mathrm{~mA} / \mathrm{mm}^{2}$. The amplitudes of reflexive responses were related to stimulus intensities according to a negatively accelerating function that differentiated low intensities better than high intensities. This was apparent in the statistical analysis of reflex force. The difference in reflex forces elicited by 0.4 and $1.1 \mathrm{~mA} / \mathrm{mm}^{2}$ was significant at $p<0.005$, whereas the difference between 1.1 and $2.5 \mathrm{~mA} / \mathrm{mm}^{2}$ was significant only at $p<0.05$.

\section{Postoperative data}

Figure 4 presents geometric means of trial durations on the escape task, averaged over the last preoperative month and the first postoperative month of testing. Each data point represents means of 80 trials delivered over 20 testing sessions. Figure 4 shows that the anterolateral chordotomy produced a clear hyposensitivity to high-intensity stimuli applied to the contralateral leg. The chordotomy did not eliminate contralateral escape responses altogether but produced a reduction in responsiveness of each animal to the moderate and high levels of stimulation. The contralateral elevation of trial durations was produced by both decreases of escape percentage and elevations of escape latency. In contrast, postoperative trial durations with stimulation of the ipsilateral leg were indistinguishable from the preoperative values for each monkey. The average change in escape percentage following chordotomy was a $67 \%$ decrease contralaterally and a $1.5 \%$ increase ipsilaterally, at $1.1 \mathrm{m \Lambda} / \mathrm{mm}^{2}$. The average change in escape latency was a $0.355 \mathrm{sec}$ increase contralaterally and a $0.02 \mathrm{sec}$ increase ipsilaterally, at $2.5 \mathrm{~mA} / \mathrm{mm}^{2}$. A strictly contralateral effect was corroborated statistically, as indicated by a significant leg $\times$ operative condition term of the
ANOVA (Table 2). The contralateral hypalgesia was maintained over several months of testing, as described by Vierck et al. (1985)

Chordotomy did not significantly alter the latencies of response on the detection task with stimulation of either leg, demonstrating that the contralateral elevation of trial durations was specific for the high intensities of stimulation presented on the escape task. The averages of the median detection latencies were 1.02 and $1.00 \mathrm{sec}$ for the left and right legs preoperatively, and the mean postoperative latencies were 0.94 and $0.95 \mathrm{sec}$.

Figure 5 presents the effects of chordotomy on detection thresholds of the four monkeys. Each point represents differences between postoperative thresholds (averaged over 1 month of testing) and preoperative thresholds (averaged over 2 or, when available, 3 months of testing) from the same leg. Three of four animals showed a slight increase in threshold on the contralateral leg (Fig. 5, circles, dashed line), and this hyposensitivity was maintained throughout the postoperative testing period. Additionally, each animal revealed a small ipsilateral decrease (squares, solid line) in threshold that was consistent postoperatively. It is unlikely that the ipsilateral change in sensitivity resulted simply from practice on the task, because thresholds dropped abruptly following chordotomy, rather than gradually over months. Comparison of the last preoperative and the first postoperative months by ANOVA revealed a significant effect of the operation for the ipsilateral leg and a significant leg $x$ operation interaction. A significant ipsilateral hypersensitivity and a slight (but insignificant) contralateral hyposensitivity resulted in a highly significant difference between the postoperative thresholds (Table 2).

Figure 6 demonstrates bilateral depression of reflexive force for each monkey, following anterolateral chordotomy. The decreased amplitudes of flexion to stimulation of the lateral calf were statistically significant for stimulus intensities below and above escape threshold (i.e., at $0.4 \mathrm{~mA} / \mathrm{mm}^{2}$ vs 1.1 and $2.5 \mathrm{~mA}$ / $\mathrm{mm}^{2}$ ). The amplitudes of reflexes from the two legs were reduced 


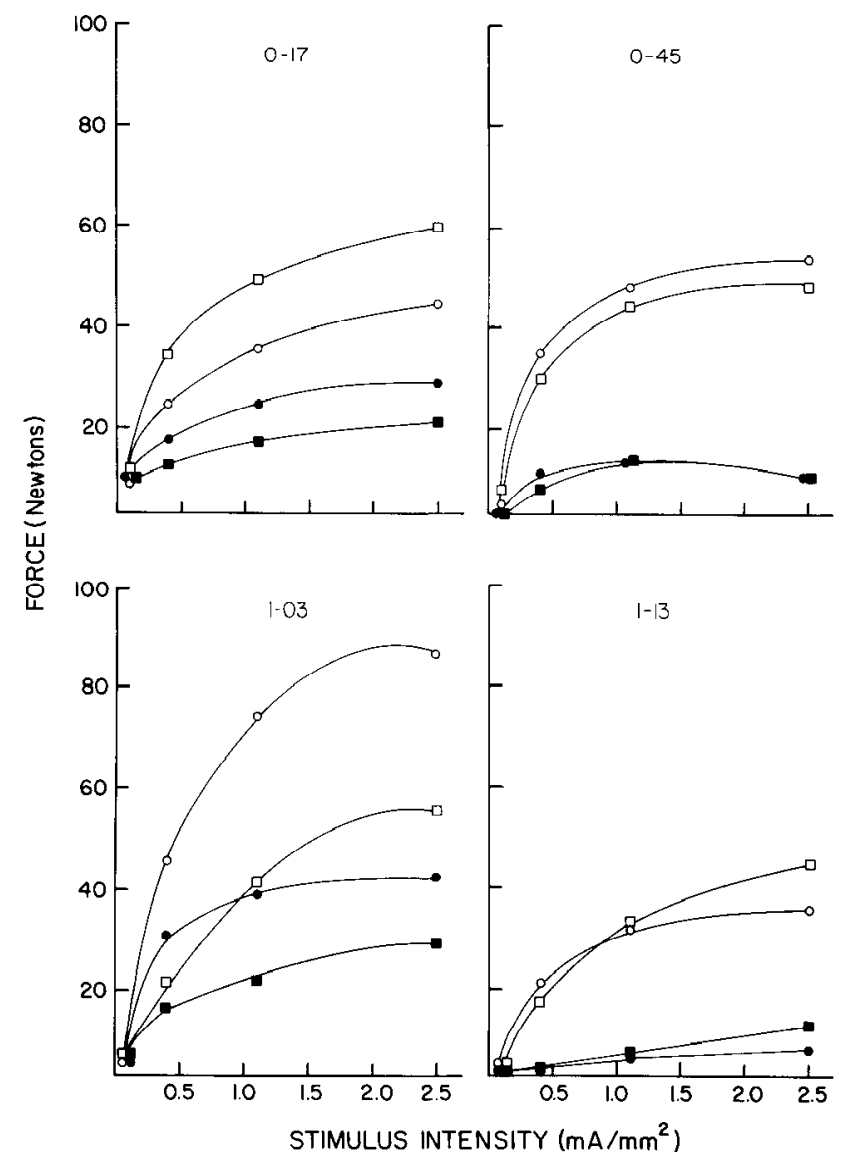

Figure 6. Reflex forces as functions of stimulus intensities presented to four monkeys on the escape task. Bilateral reductions of postoperative reflex amplitude (solid symbols) were observed for each animal. Other symbols as in Figure 4.

comparably by chordotomy, as indicated by a significant effect of the operation (bilaterally), but no difference between the legs preoperatively or postoperatively (i.e., no leg $x$ operation interaction; Table 2).

Figure 7 demonstrates that the force of operant escape responding was decreased by chordotomy. One monkey (0-45) showed the effect only with contralateral stimulation, and operant force was decreased for the other three monkeys with stimulation of either leg. These results suggest that several effects on escape force were confounded: (1) a reduction of operant vigor based on a reduction in perceived intensity of the sensation evoked by stimulation contralateral to the lesion (shown by all monkeys), and (2) a reduction of motoric output based on interruption of the ascending axons that influence volitional driving of motoneurons. The latter effect was obtained from three monkeys with stimulation ipsilateral to the lesion. The animals were not videotaped to determine the consistency of operant responding with one or the other hand, but observation of these animals during the training period indicated a preference for responding with the right (ipsilateral) hand.

\section{Discussion}

Although a large number of investigations have attempted to assess pain and analgesia in laboratory animals, few studies have measured responses to nonpainful stimuli to determine whether alterations in behavior result from changes in pain perception rather than other sensory or motor effects. For example, thresholds for responding on shock-titration paradigms generally approximate the detection thresholds obtained in the present investigation, when expressed in terms of current density (Dykstra,
1980; Weiss and Laties, 1970; Yaksh and Rudy, 1977). This is of concern when the intention of the titration procedure is to evaluate pain reactions, and thus it is important to independently define thresholds for detection and aversion. The most stringent comparison involves matching stimulus sources and responses on two tasks that differ primarily in reinforcement contingencies. This report presents such a procedure: The detection task uses the same form of stimulation, the same testing apparatus, and the same behavioral response as the pain task. A similar approach has been used successfully with thermal stimulation (Hayes et al., 1981; Hoffman et al., 1981).

The monkeys demonstrated that they distinguished between the pain (escape) task and the non-pain (detection) task by exhibiting escape thresholds that were 50-100 times the intensity of detection thresholds (greater than $0.4 \mathrm{~mA} / \mathrm{mm}^{2}$ vs less than $0.01 \mathrm{~mA} / \mathrm{mm}^{2}$ ). These differences in threshold were maintained over months of testing, which can be attributed to the contingencies presented by each component of the task. On detection trials, the most efficient strategy for acquiring positive reinforcement was to respond to each detectable stimulus and withhold responses in the absence of a sensation. Emission of responses on escape trials did not affect the intensity or timing of stimulation on subsequent trials, and therefore, the only advantage consisted of immediate termination of ES.

Support for the assumption that the escape task involved responses to painful stimuli comes from human psychophysical studies using equipment and procedures very similar to those used here (Vierck et al., 1983b). Pain thresholds (as determined by verbal descriptors) and escape thresholds of human subjects are comparable to the escape thresholds of these monkeys. Furthermore, both human and monkey subjects reveal decreasing trial durations and increasing forces of operant escape responses as a function of $\mathrm{ES}$ intensities from 0.4 to $2.5 \mathrm{~mA} / \mathrm{mm}^{2}$. The $2.5 \mathrm{~mA} / \mathrm{mm}^{2}$ stimulus was eight times the level producing $50 \%$ responses by normal subjects, and the reliable, fast, and forceful responses to the strongest intensity indicate that it was clearly a suprathreshold for pain.

Following unilateral, ventrolateral chordotomy, the monkeys exhibited a marked reduction in frequency, increase in latency, and decrease in force of escape responses to high intensities of contralateral stimulation. For each animal, the trial-duration measure indicated that chordotomy reduced reactivity to the strong stimulus $\left(2.5 \mathrm{~mA} / \mathrm{mm}^{2}\right)$ to levels normally elicited by the intermediate intensity, and reactions to $1.1 \mathrm{~mA} / \mathrm{mm}^{2}$ approximated normal reactions to stimulation near the escape threshold $\left(0.4 \mathrm{~mA} / \mathrm{mm}^{2}\right)$. In contrast, the latencies and forces of detection responses were unaffected by the lesions, and detection thresholds remained well below escape thresholds, demonstrating a selective hypoalgesia (hypalgesia). This behavioral pattern confirms reports from chordotomy patients who describe (a) a contralateral loss or reduction in pain sensations elicited by electrical, mechanical, or thermal stimulation (Hyndman and Wolkin, 1943; King, 1957; Nathan and Smith, 1979; White and Sweet, 1969), and (b) small, if any, alterations of tactile sensitivity (White and Sweet, 1969).

The pain loss following a unilateral chordotomy in humans is restricted to body sites contralateral to the lesion, and a strictly lateralized hypalgesia was revealed by the durations of electrical stimulation tolerated by the monkeys on the escape task. That is, trial durations on the escape task were significantly elevated postoperatively, with stimulation of the left side (relative to preoperative durations from either leg and to postoperative values from stimulation of the right leg). Therefore, the presence and timing of operant responses (by a limb supplied by afferent fibers that enter the spinal cord above the lesion) constitute approximate measures of the effects of anterolateral chordotomy on somatic sensations.

The decrease of operant pain reactivity following chordotomy 

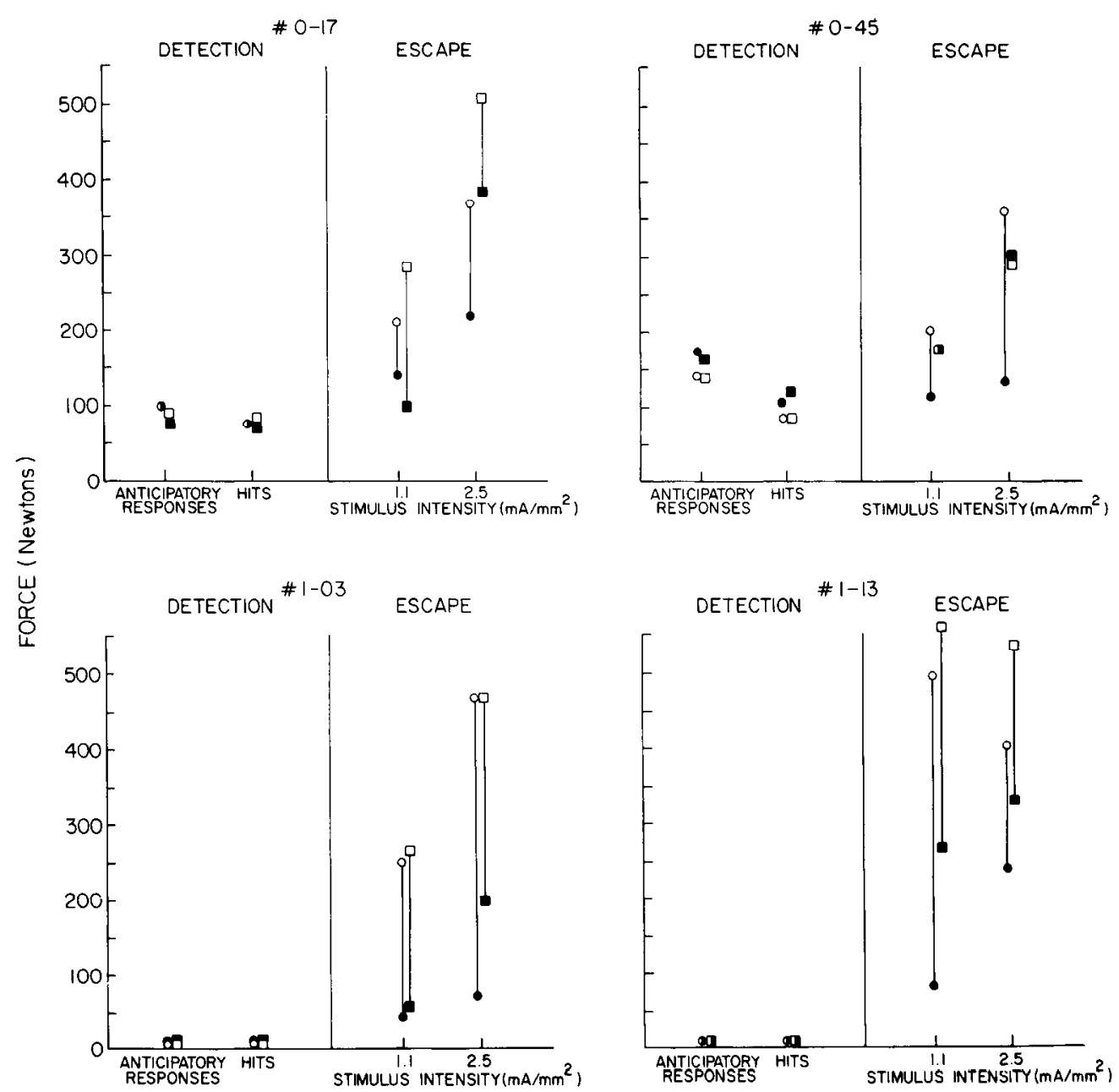

Figure 7. Operant forces exerted on anticipatory and correct responses on the detection task and during escape responses to 1.1 or $2.5 \mathrm{~mA} / \mathrm{mm}^{2}$. Preoperative values are indicated by open symbols (circles $=$ left leg; squares $=$ right leg), and closed symbols indicate postoperative forces. Differences between preoperative and postoperative values from each leg are indicated by vertically connecting lines.

can be presumed to result from transection of spinothalamic (and possibly spinoreticular) axons that originate from the contralateral spinal gray at the lumbosacral enlargement (Willis and Coggeshall, 1978; indicated by pathway $a$ in Fig. 8). Many spinothalamic projection cells and anterolateral axons with contralateral receptive fields receive predominant inputs from pcripheral nociceptors (Kumazawa and Perl, 1978; Price and Mayer, 1975; Willis et al., 1974), accounting for a preferential attenuation of nociception following chordotomy. However, lowthreshold tactile inputs to anterolateral axons or spinothalamic projection cells also have been documented (Applcbaum et al., 1975; Price et al., 1978; Willis et al., 1974), lending credence to reports of subtle, contralateral deficits of touch detection in human patients following chordotomy (Walker, 1940; White and Sweet, 1969), and leading to the expectation that slight, contralateral elevations of detection thresholds would be observed for the monkeys.

Comparing postoperative detection thresholds from stimulation of the left and right legs, the contralateral values were uniformly and significantly higher over months of testing. Comparing postoperative performance with preoperative values, the lesion slightly (but insignificantly) increased contralateral detection thresholds and clearly decreased ipsilateral thresholds. The latter effect, an ipsilateral hypersensitivity, could have been a factor in reports of deteriorated contralateral sensitivity by human chordotomy patients, for whom detailed comparisons of preoperative and postoperative detection capacities were not available. Thus, the ventral spinal quadrant (including spinothalamic axons in both the anterolateral and ventral columns) is not necessary for detection of light cutaneous stimulation. In practical terms of threshold sensitivity for light tactile stimulation, the spinal lemniscal and spinothalamic pathways are redundant in the sense that obvious impairments are not produced by ipsilateral or contralateral lesions of the spinal cord (Vierck, 1977, 1984; this study).

An ipsilateral hypersensitivity can be expected to occur from involvement of descending axons in the anterolateral column that are inhibitory to inputs onto dorsal horn neurons (Crutcher and Bingham, 1978; Westlund et al., 1984; Willcockson et al., 1984; connection $c$ in Fig. 8). However, in relation to suppositions that a descending noradrenergic pathway in the anterolateral column is preferentially inhibitory to nociceptive inputs (Belcher et al., 1978; Engberg and Ryall, 1966; Sasa et al., 1977; Segal and Sandberg, 1977; Yaksh and Reddy, 1981), it is important to note that ipsilateral detection thresholds were decreased in monkeys that did not give evidence for ipsilateral hyperactivity to strong stimulation on the escape task. Consistent with this result, stimulation of brain stem structures that modulate nociceptive responses can inhibit non-nociceptive inputs to somatosensory projection cells (Dostrovsky, 1980; Kajander et al., 1984), and previous behavioral evidence includes threshold procedures that assess reactivity to non-nociceptive stimulation (Reddy and Yaksh, 1980; Yaksh and Reddy, 1981; see Vierck and Cooper, 1984). However, studies involving phasic activation of descending systems indicate that sensitivity is decreased over a wide range of stimulus intensities (including painful stimuli). Investigations are needed that compare the effects of similar manipulations on behaviors that differentiate sensitivities to nociceptive and non-nociceptive stimulus intensities. 


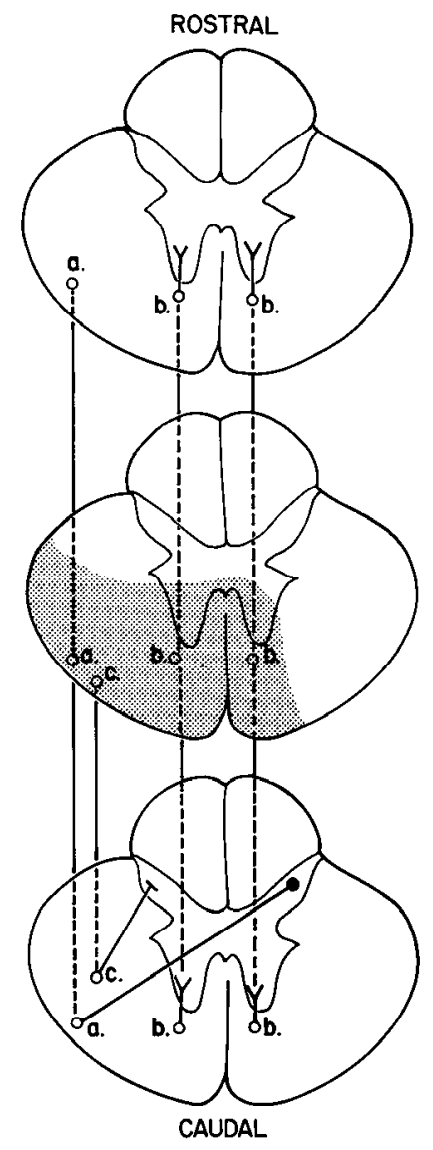

Figure 8. Schematic representation of the connections discussed in terms of each of the effects observed following chordotomy. Stippled area, approximate extent of the lesions to one anterolateral column and both ventral columns. Connection $a$, spinothalamic (and spinoreticular) axons that were interrupted contralateral to their spinal origin, producing a substantial contralateral elevation of escape latencies and a subtle elevation of detection thresholds. Rostral connections, $b$, represent propriospinal axons that were interrupted bilaterally and could have contributed to a disfacilitation of motoneurons, leading to a reduction in the force of normally vigorous operant responses by a forelimb. Caudal connections, $b$, represent comparable descending axons of the propriospinal system. Interruption of these axons may have produced the bilateral reduction in force of normally vigorous reflexive responses. Connection $c$ represents axons descending from the brain stem that were interrupted unilaterally, possibly leading to a subtle, ipsilateral reduction of detection thresholds.

The ipsilateral decrease in detection thresholds following chordotomy has implications for the nature of tonic influences of descending anterolateral axons, but it probably does not reveal effects resulting from phasic activation of descending systems of control. That is, even if descending inhibitory systems are activated by nociceptive stimulation (Guyenet, 1980; Korf et al., 1977; Moolenaar et al., 1976; Yaksh et al., 1984), a minimum of $20 \mathrm{sec}$ separates escape and detection trials, and phasic inhibition from brain stem stimulation appears to last on the order of $250 \mathrm{msec}$ (Kajander et al., 1984). The selective lowering of thresholds for detection of ipsilateral ES contrasts with a tonic increase in reactivity to painful electrical stimulation that has been observed following ipsilateral lesions of the dorsolateral columns in monkeys (Vierck et al., 1971). That is, tonic inhibitory functions mediated by descending dorsolateral and ventrolateral axons appear to exert preferential influences on nociceptive and non-nociceptive coding, respectively.

Reflexive reactions are often used as indications of pain, and some reflexive measures may well correlate with the intensity of pain sensations (Willer, 1984). However, the effects of chordotomy in the present study demonstrate that reflexive responses to strong stimulation can reveal modulations that differ from those operating on sensory projection neurons at the same spinal level. Following anterolateral chordotomy, the monkeys' reflexive reactions were bilaterally reduced in amplitude, in contrast to effects on stimulus detection and pain reactivity that were clearly lateralized. In addition, the magnitude and direction of the sensory effects depended on stimulus intensity (i.e., ipsilateral hypersensitivity was seen with low stimulus intensities, and contralateral hyposensitivity was observed with strong stimulation), but reduced amplitudes of segmental reflexes were observed with stimulation at intensities above or below escape thresholds.

The effect of chordotomy on reflexive vigor contrasts with the consequences of lateral hemisection, which produces hyperreflexia in response to stimulation of muscular or cutaneous afferents (Aoki et al., 1976; Hultborn and Malmsten, 1983; Murray and Goldberger, 1974). The hyperreflexia from lateral hemisection has been attributed to interruption of descending pathways in the dorsolateral fasciculus (Holmqvist and Lundberg, 1961) that were spared by the chordotomies. The spinal lesions shown in Figure 4 interrupted the ventral columns bilaterally, involving ascending and descending propriospinal conncctions between different segments of the ventral horn (Molenaar and Kuypers, 1978; Nathan and Smith, 1959; Tower et al., 1941). The bilateral ventral lesions could have accounted for hyporeflexia with stimulation of either leg (schematized by Fig. 8, connections $b$, caudal). Consistent with the effect on reflexive force, chordotomy reduced the force of normally vigorous operant escape responses to ipsilateral stimulation, indicating that ascending axons in the ventral quadrant of the spinal cord normally facilitate motoric generation of high force (represented in Fig. 8 by connections $b$, rostral).

\section{References}

Aoki, M., S. Mori, and B. Fujimori (1976) Exaggeration of knee-jerk following spinal hemisection in monkeys. Brain Res. 197: 471-485.

Applebaum, A. E., J. E. Beall, R. D. Foreman, and W. D. Willis (1975) Organization and receptive fields of primate spinothalamic tract neurons. J. Neurophysiol. 38: 572-586.

Belcher, G., R. W. Ryall, and R. Shaffner (1978) The differential effects of 5,6-hydroxytryptamine, noradrenaline and raphe stimulation on nociceptive and non-nociceptive dorsal horn interneurons in the cat. Brain Res. 151: 307-332.

Brown-Sequard, E. (1868) Lectures on the physiology and pathology of the nervous system. Lancet 2: 593-596, 755-757, 821-823.

Bruning, J. L., and B. L. Kintz (1968) Computational Handbook of Statistics, Scott, Foresman, Glenview, IL.

Cornsweet, T. N. (1962) The staircase method in psychophysics. Am. J. Psychol. 75: 485-591.

Crutcher, K. A., and W. G. Bingham (1978) Descending monoaminergic pathways in the primate spinal cord. Am. J. Anat. 153: 159164.

D'Amour, F. E., and D. L. Smith (1941) A method for determining loss of pain sensation. J. Pharmacol. Exp. Ther. 72: 74-79.

Dostrovsky, J. O. (1980) Raphe and periaqueductal gray induced suppression of non-nociceptive neuronal responses in the dorsal column nuclei and trigeminal sub-nucleus caudalis. Brain Res. 200: 184189.

Dykstra, L. (1980) Discrimination of electric shock: Effects of some opioid and nonopioid drugs. J. Pharmacol. Exp. Ther. 2123: 234240.

Edwards, A. L. (1985) Experimental Design in Psychological Research, Harper and Row, New York.

Engberg, I., and R. W. Ryall (1966) The inhibitory action of noradrenaline and other monoamines on spinal neurones. J. Physiol. (Lond.) 185: 298-332.

Evans, W. O. (1961) A new technique for the investigation of some analgesic drugs on a reflexive behavior in the rat. Psychopharmacology (Berlin) 3: 51-54 
Gescheider, G. A. (1976) Psychophysics Method and Theory, Lawrence Erlbaum, New York

Guyenet, P. G. (1980) The coeruleospinal noradrenergic neurons: Anatomic and electrophysiologic studies in the rat. Brain Res. 189:121133.

Hayes, R. L., R. Dubner, and D. S. Hoffman (1981) Neuronal activity in medullary dorsal horn of awake monkeys trained in a thermal discrimination task. II. Behavioral modulation of responses to thermal and mechanical stimuli. J. Neurophysiol. 46: 428-444.

Head, H., and T. Thompson (1906) The grouping of afferent impulses within the spinal cord. Brain 29: 537-741.

Hoffman, D. S., R. Dubner, R. L. Hayes, and T. Medlin (1981). Neuronal activity in medullary dorsal horn of awake monkeys trained in a thermal discrimination task. I. Response to innocuous and noxious thermal stimuli. J. Neurophysiol. 46: 409-427.

Holmqvist, B., and A. Lundberg (1961) Differential supraspinal control of synaptic actions evoked by volleys in the flexion reflex afferents in alpha motoneurons. Acta Physiol. Scand. 54 (Suppl. 186): 1-51.

Hultborn, H., and J. Malmsten (1983) Changes in segmental reflexes following chronic spinal cord hemisection in the cat. I. Increased monosynaptic and polysynaptic ventral root discharges. Acta Physiol. Scand. 119: 405-422.

Hyndman, O. R., and J. Wolkin (1943) Anterior chordotomy. Arch. Neurol. Psychiatry 50: 129-148.

Jacquet, Y. F., and A. Lajtha (1976) The periaqueductal gray: Site of morphine analgesia and tolerance as shown by 2 -way cross-tolerance between systemic and intracerebral injections. Brain Res. 103: 501513.

Kajander, K. C., T. J. Ebner, and J. R. Bloedel (1984) Effects of periaqueductal gray and raphe magnus stimulation on the responses of spinocervical and other ascending projection neurons to non-noxious inputs. Brain Res. 291: 29-37.

Kennard, M. A. (1954) The course of ascending fibers in the spinal cord of the cat essential to the recognition of painful stimuli. J. Comp. Neurol. 100: 511-524.

Kevetter, G. A., and W. D. Willis (1984) Collateralization in the spinothalamic tract: New methodology to support or deny phylogenetic theories. Brain Res. Rev. 7: 1-14.

King, R. B. (1957) Postchordotomy studies of pain threshold. Neurology (Minn.) 7: 610-614

Korf, J., B. S. Bunney, and G. K. Aghajanian (1977) Noradrenergic neurons: Morphine inhibition of spontaneous activity. Eur. J. Pharmacol. 25: 369-372.

Kumazawa, T., and E. R. Perl (1978) Excitation of marginal and substantia gelatinosa neurons in the primate spinal cord: Indications of their place in dorsal horn functional organization. J. Comp. Neurol. 177: 417-434.

Lineberry, C. G. (1981) Laboratory animals in pain research. In Methods in Animal Experimentation, W. I. Gay, ed., pp. 237-311, Academic, New York.

May, W. P. (1906) The afferent path. Brain 29: 742-803.

Mehler, W. R. (1969) Some neurological species differences-A posteriori. Ann. NY Acad. Sci. 167: 424-468.

Molenaar, I., and H. G. J. M. Kuypers (1978) Cells of origin of propriospinal fibers and of fibers ascending to supraspinal levels. A HRP study in cat and Rhesus monkey. Brain Res. 152: 429-450.

Moolenaar, G. M., J. A. Holloway, and C. O. Trouth (1976) Responses of caudal raphe neuron to peripheral somatic stimulation. Exp. Neurol. 53: 304-314.

Murray, M., and M. Goldberger (1974) Restitution of function and collateral sprouting in the cat spinal cord: The partially hemisected animal. J. Comp. Neurol. 158: 19-36.

Nathan, P. W., and M. C. Smith (1959) Fasciculi proprii of the spinal cord in man. Brain 82: 610-668.

Nathan, P. W., and M. C. Smith (1979) Clinico-anatomical correlation in anterolateral cordotomy. In Advances in Pain Research and Therapy, Vol. 3, J. J. Bonica, J. C. Liebeskind, and D. G. Albe-Fessard, eds., pp. 921-926, Raven, New York.

Petren, K. (1902) Ein Beitrag für Pfage vom Verlaufe der Bahnen der Hautsinne im Ruckenmarke. Scand. Arch. Physiol. 13: 9-98.

Price, D. D., and D. J. Mayer (1975) Neurophysiological characterization of anterolateral quadrant neurons subserving pain in $M . m u$ latta. Pain 1: 59-72.

Price, D. D., R. L. Hayes, M. A. Ruda, and R. Dubner (1978) Spatial and temporal transformations of input to spinothalamic tract neurons and their relation to somatic sensations. J. Neurophysiol. 41: 933947.

Reddy, S. V. R., and T. L. Yaksh (1980) Spinal noradrenergic terminal system mediates antinociception. Brain Res. 189: 391-401.

Sasa, M., K. Munekyo, Y. Osuni, and S. Takori (1977) Attenuation of morphine analgesia in rats with lesions of the locus coeruleus and dorsal raphe nuclei. Eur. J. Pharmacol. 42: 53-62.

Segal, M., and D. Sandberg (1977) Analgesia produced by electrical stimulation of catecholamingeric nuclei in the rat brain. Brain Res. 123: 369-372.

Tower, S., D. Bodian, and H. Howe (1941) Isolation of intrinsic and motor mechanisms of the monkey's spinal cord. J. Neurophysiol. 4: 338-397.

Vierck, C. J., Jr. (1977) Absolute and differential sensitivities to touch stimuli after spinal cord lesions in monkeys. Brain Res. 146: 279294.

Vierck, C. J., Jr. (1984) The spinal lemniscal pathways. In Handbook of the Spinal Cord, Vols. 2 and 3: Anatomy and Physiology, R. A. Davidoff, ed., pp. 674-750, Marcel Dekker, New York.

Vierck, C. J., Jr., and B. Y. Cooper (1984) Guidelines for assessing pain reactions and pain modulation in laboratory animal subjects. In Advances in Pain Research and Therapy, L. Kruger and J. C. Liebeskind, eds., pp. 305-322, Raven, New York.

Vierck, C. J., Jr., and M. M. Luck (1979) I oss and recovery of reactivity to noxious stimuli in monkeys with primary spinothalamic chordotomies, followed by secondary and tertiary lesions of other cord sectors. Brain 102: 233-248.

Vierck, C. J., Jr., B. Y. Cooper, and R. H. Cohen (1983a) Human and non-human primates' reactions to painful electrocutaneous stimuli and to morphine. In Animal Pain Perception and Alleviation, R. L. Kitchell and H. H. Erickson, eds., pp. 117-132, American Physiological Society, Washington, DC

Vierck, C. J., Jr., B. Y. Cooper, O. Franzen, L. A. Ritz, and J. D. Greenspan (1983b) Behavioral analysis of CNS pathways and transmitter systems involved in conduction and inhibition of pain sensations and reactions in primates. In Progress in Psychobiology and Physiological Psychology, Vol. 10, J. Sprague and A. Epstein, eds., pp. 113-165, Academic, New York.

Vierck, C. J., Jr., J. D. Greenspan, L. A. Ritz, and D. C. Yeomans (1985) The spinal pathways contributing to the ascending conduction and the descending modulation of pain sensations and reactions. In Spinal Afferent Processing, T. Yaksh, ed., Plenum, New York.

Vierck, C. J., Jr., D. M. Hamilton, and J. I. Thornby (1971) Pain reactivity of monkeys after lesions to the dorsal and lateral columns of the spinal cord. Exp. Brain Res. 13: 140-158.

Walker, A. E. (1940) The spinothalamic tract in man. Arch. Neurol. Psychiatry 43: 284-298.

Weiss, B., and V. G. Laties (1970) The psychophysics of pain and analgesia in animals. In Animal Psychophysics, W.C. Stebbins, ed., pp. 185-210, Appleton-Century-Crofts, New York.

Westlund, K. N., R. M. Bowker, M. G. Ziegler, and J. D. Coulter (1984) Origins and terminations of descending noradrenergic projections to the spinal cord of monkey. Brain Res. 292: 1-16.

White, J. C., and W. H. Sweet (1969) Pain and the Neurosurgeon, Charles C Thomas, Springfield, IL.

Willcockson, W. S., J. M. Chung, Y. Hori, K. H. Lee, and W. D. Willis (1984) Effects of iontophoretically released amino acids and amines on primate spinothalamic tract cells. J. Neurosci. 4: 732-740.

Willer, J.-C. (1984) Nociceptive flexion reflex as a physiological correlate of pain sensation in humans. In Pain Measurement in Man, B. Bromm, ed., pp. 87-110, Elsevier, Amsterdam.

Willis, W. D., and R. E. Coggeshall (1978) Sensory Mechanisms of the Spinal Cord, Plenum, New York.

Willis, W. D., D. L. Trevino, J. D. Coulter, and R. A. Maunz (1974) Responses of primate spinothalamic tract neurons to natural stimulation of hindlimb. J. Neurophysiol. 37: 358-372.

Wood, P. L. (1984) Animal models in analgesic testing. In Analgesics: Neurochemical, Behavioral and Clinical Perspectives, M. Kuhar and G. Pasternak, eds., pp. 175-194, Raven, New York.

Woolfe, G., and A. D. MacDonald (1944) The evaluation of the analgesic action of pethidine hydrochloride (Demerol). J. Pharmacol. Exp. Ther. 80: 300-307.

Yaksh, T. L., and S. V. R. Reddy (1981) Studies in the primate on the analgetic effects associated with intrathecal actions of opiates, alpha-adrenergic agonists and baclofen. Anesthesiology 54:451-467. 
Yaksh, T. L., and T. A. Rudy (1976) Analgesia mediated by a direct spinal action of narcotics. Science 192: 1357-1358.

Yaksh, T. L., and T. A. Rudy (1977) A dose ratio comparison of the interaction between morphine and cyclazocine with naloxone in thesus monkeys on the shock titration task. Eur. J. Pharmacol. 46: 8392.
Yaksh, T. L., J. R. Howe, and G. J. Harty (1984) Pharmacology of spinal pain modulatory systems. In Advances in Pain Research and Therapy, Vol. 7, C. Benedetti, ed., pp. 57-70, Raven, New York. 